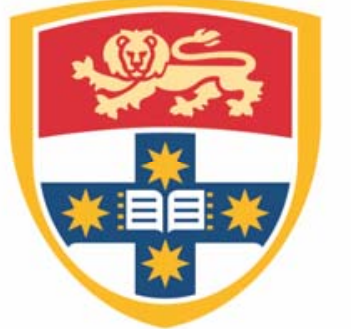

\title{
THE UNIVERSITY OF
}

SYDNEY

Economics Working Paper Series

$$
2015-6
$$

Canonical Riskless Choice Over Bundles:

Aint No Reference Point Here

Hui-Kuan Chung, Paul Glimcher

\& Agnieszka Tymula

April 2015 


\title{
Canonical Riskless Choice Over Bundles: Aint No Reference Point Here
}

\author{
Hui-Kuan Chung ${ }^{1}$, Paul Glimcher ${ }^{2 *}$, Agnieszka Tymula ${ }^{2,3}$
}

\begin{abstract}
:
Prospect Theory (Kahneman and Tversky 1979), one of the most prominent models for valuation of goods and money, presumes that people have convex utility over gains and concave utility over losses; a discontinuity at something like the current wealth level or reference point. This reflects a behavioral pattern confirmed in hundreds of experimental studies where in lottery tasks people show decreasing marginal utility over gains (risk aversion) and increasing marginal utility (risk seeking) over losses relative to this "reference". Although it is widely assumed that a reference point is also required to describe riskless choices made over bundles of goods, there is less empirical evidence for this claim. In this paper, using incentive-compatible experimental methods, we challenge the generality of this assumption. We find that in riskless choice over bundles of goods in a canonical budget set experiment, gain-loss asymmetries are not observed even while in interleaved lottery tasks the reference point is observed, in the same subjects. Our results suggest a discontinuity between the value functions inferred from choices over standard lotteries and the utility functions inferred from indifference curves in riskless choice.
\end{abstract}

Keywords: Indifference curve; Riskless Choice; Reflection effect; Reference point; Losses JEL codes: D81

\footnotetext{
${ }^{1}$ Department of Psychology, New York University, 6 Washington Place, room 907, New York, NY 10003, USA.

${ }^{2}$ Institute for the Interdisciplinary Study of Decision Making, 300 Cadman Plaza West, 7th floor, Brooklyn, NY 11201, USA.

${ }^{3}$ School of Economics, University of Sydney, H04 - Merewether, room 370, Sydney, NSW 2006, Australia.

*Correspondence to: Paul Glimcher, pg3@nyu.edu, phone: (212) 998-3904, fax: (212) 995-4011.
} 


\section{Introduction}

Since Kahneman and Tversky (1979) proposed prospect theory, numerous studies have found that the evaluation of changes in wealth by individuals is best modeled (in a positive sense) as gains and losses with respect to a reference point rather than as being computed over total wealth (Köszegi and Rabin 2006; Tversky and Kahneman 1992) ${ }^{1}$. The tilted, S-shaped utility function Kahneman and Tversky proposed rests fundamentally on the notion of a reference point, and this is an insight which is core to several aspects of prospect theory. It shows up both in the "reflection effect" that captures diminishing marginal utility for gains and an increasing marginal utility for losses, and in "loss aversion" that captures the notion that losses loom larger than gains of equal size.

While prospect theory was originally intended specifically as a theory of choice under risk, subsequent work has applied many of the elements of prospect theory to the understanding of riskless choice (Thaler 1980; Kahneman et al. 1991; Thaler et al. 1997). Interestingly, however, we know of no direct evidence which supports the existence of the reference point for choices made under conditions of certainty. The "endowment effect" (Knetsch 1989; Thaler 1980) is often taken as compatible with loss aversion across a fixed reference point under conditions of riskless choice, but a reference point is not the only possible explanation for this phenomena (Plott and Zeiler 2005).

Prospect theory as originally proposed was, of course, intended to address positive failures of the expected utility model (Von Neumann and Morgenstern 1944) that were observed when predicting the decisions under conditions of uncertainty. Indeed, the title of Kahnemann and Tversky's classic 1979 paper is "Prospect Theory: An Analysis of Decision under Risk" and in their 1992's paper, Kahneman and Tversky clearly stated that their theory was aimed to specifically engage decision-making under risk: “(...) we presented a model of choice, called prospect theory, which explained the major violations of expected utility theory in choices between risky prospects with a small number of outcomes". While there is little doubt that prospect theory can predict many behavioral patterns of choice under risk that expected utility theory cannot, it remains unclear whether prospect theory and its reference point provide a parsimonious description of riskless choices.

It was largely Thaler (1980) who advanced the notion that some inconsistent behaviors observed even when there is no risk involved could be explained by a reference point, via Prospect Theory. He noted that the widely observed endowment effect (the phenomenon that people value an object more when they own it) can be explained by loss aversion relative to a current reference point. While this is true, we note an important point, the other key feature of the prospect theory,

\footnotetext{
${ }^{1}$ Friedman and Savage (1948) accounted for the dependence of risk attitude on current wealth without requiring a reference point, but a large body of evidence now suggests that greater flexibility with regard to wealth-level is required than Friedman and Savage had imagined.
} 
the change of the utility curvature for gains and losses, has never been empirically explored in the domain of riskless choice. This is exactly what we aim to do in this paper.

To see that the assumption of the increasing marginal utility for losses with regard to the reference point seems at the very least questionable for choice under certainty, imagine the following situation: You are sailing and have some food and beverage supplies for the journey. You have 8 boxes of crackers and 8 boxes of juice with you. Suddenly, there is an accident and you have to dispose of half of your supplies to keep the boat from sinking. What bundle of 8 goods would you choose to retain? Most reasonable parameterizations of prospect theory would clearly predict that because of the reference point (and its increasing marginal utility in losses for all goods relative to that point), you should prefer retaining all of one type of good to any mixed bundles $^{2}$. Either you would throw away all of your juice or you would throw away all crackers, taking advantage of the accelerating curvature of the negative-going utility function. Although a chooser who showed increasing marginal utilities for all goods in the domain of losses would be well described with indifference curves convex to the origin, the pattern of substitution this suggests does not seem to us like an obvious prediction at all.

In this paper, using two incentive-compatible experimental tasks in the gain and loss domains, we investigated whether marginal utility is increasing or decreasing in interleaved riskless and risky choice tasks conducted on the same experimental participants. Consistent with prospect theory and numerous previous studies that involved choices over risky lotteries, we found clear evidence of the reflection effect, and hence the reference point, under conditions of risky choice. Our participants showed diminishing marginal utility in gains and increasing marginal utility in losses when asked to choose between risky lotteries over snack food and beverage rewards. The same participants, when asked to make riskless trade-offs between snacks and beverages in the gain domain showed the usual pattern of diminishing marginal utility in gains (or more precisely, they showed convex indifference curves relative to the origin in a budget space). But when asked to make riskless trade-offs in the loss domain over the same goods, they also showed what appears to be diminishing marginal utility. (Again, more precisely, they showed no change in the curvature of their indifference curves as choices crossed into the loss domain.) Thus in the riskyloss domain our participants showed increasing marginal utilities over both snacks and beverages but in the riskless-loss domain they showed diminishing marginal utility (or more precisely diminishing marginal rates of substitution). This latter finding is, we suggest, inconsistent with prospect theory and clearly fails to demonstrate the existence of a reference point during canonical riskless choice over bundles. We thus infer that there is no reference point when subjects make riskless choices over bundles.

\footnotetext{
${ }^{2}$ One could imagine such an extreme pattern of substitution that a chooser was willing to forego the increased marginal utility offered by having a larger number of one class of goods, but for most of the classes of indifference curves that have been empirically observed, this prediction is a robust element of positive theory.
} 


\section{Experimental Design}

In the experiment the participants made a series of choices between different bundles of goods that they could gain (gain condition) or lose (loss condition). There were two types of choice tasks. The riskless choice task was designed to assess the shape of the indifference curve (and hence the marginal rates of substitution between two goods), revealing whether the reflection effect occurs when there is no uncertainty. The risky choice task served as a control to verify that our participants showed the widely observed reflection effect (decreasing marginal utility in gains, increasing in losses) for snacks and beverages in choice under risk.

In both of the tasks the participants made decisions over different bundles that consisted of some quantity of beverage and snack. Before the experiment began, we gave participants a selection of beverages and snacks to choose from to ensure that they liked the products that constituted the reward in our experiment. The available beverages were: Horizon Organic UHT milk, Juicy Juice apple juice, and Juicy Juice orange juice. The snacks were: Lindt chocolates, a small package of Pepperidge farm brand Goldfish crackers, and Nature Valley granola bars. Upon arrival participants picked their favorite beverage and snack, understanding that a bundle of these goods would serve as partial payment for participation. As it was possible to loose some quantity of the beverage and snack in the experiment, to satisfy the ethics board requirements at the very beginning of the study we endowed participants with 8 of their preferred beverage and 8 of their preferred snack, an amount equal to the maximum possible loss in the experiment ${ }^{3}$.

After participants had received their endowment, they read the instructions (available in the appendix A). They were given an opportunity to ask questions, answered several comprehension questions, and completed several practice rounds, all to make sure they were familiar with the experimental procedure before starting the experimental session.

Participants performed simple binary choices in all tasks. The order in which the participants completed the riskless and risky choice task was randomized. The order of gain condition and loss condition within each task was randomized as well. There was no time limit in the experiment, so participants could take their time to decide. In total, there were 308 experimental trials plus 36 test trials, all mixed together (participants did not know in advance how many trials would be presented in the experiment). The experimental trials were used to estimate the utility function curvature and the curvature of the indifference curves. An embedded set of "test trials" involved first-order stochastically dominated options and allowed us to screen for participants whose preferences could not be represented by a monotonic utility function. The experimental

\footnotetext{
${ }^{3}$ While the use of an endowment to study losses is always a concern in laboratory studies, there is reason to believe it is effective (Etchart-Vincent and l'Haridon 2011). Our data, presented below, clearly indicate the expected pattern of increasing marginal utilities over losses in the domain of risky choice. Thus our endowed subjects did appear to show "standard" referencedependent choice phenomena.
} 
program randomly determined which option was shown on the left side and right side of the display screen and this varied from trial-to-trial and from participant-to-participant.

At the end of the experiment, participants were paid according to their choice in one randomly selected trial. In addition to the beverage and snack rewards, each subject received a $\$ 20$ participation fee.

\section{Riskless choice task}

To estimate the shape of the indifference curve (and the utility function it implied) under conditions of certainty, we asked participants to choose between two bundles containing different quantities of each product. Figure 1 shows a typical gain and a typical loss trial. In the left panel of Figure 1 the subject is asked to decide whether she would prefer to receive a bundle of 4 milk boxes and 4 chocolates or a bundle of 1 milk box and 7 chocolates. In the right panel, the subject is asked to decide whether she prefers to lose (from her endowment) a bundle of 4 milk boxes and 4 chocolates or to lose a bundle of 1 milk boxes and 7 chocolates. The choices are not obvious. Each decision involves a tradeoff between the two goods; having more of one always results in having less of the other one. To ensure that participants could differentiate between the loss and gain condition we used textual ('gain' vs 'lose'), symbolic (+ versus -) and color (green versus red) cues all together in the displays. The complete set of choices presented to each subject is shown in Table 1 .

Figure 2A graphically presents the set of all questions we asked in the gain domain, and should be helpful in understanding the rationale behind the experimental design. Each of the dots in the graph represents one particular bundle of snacks and beverages that was offered. The black dot represents a "fixed option" of 4 units of beverage and 4 units of snack that was available in every one of the gain trials (in the left column in Table 1). For the gain trials, subjects chose between this fixed option and a second varying option. To form a full gain domain choice set of 32 trials, the fixed option (black dot) was paired once with every other dot in the graph (every combination of goods from the right column in Table 1). For example, when paired with the bundle marked with an orange dot in Figure 2A, this condition corresponds to the choice situation shown in Figure 1A. Figures $2 \mathrm{~B}$ and $2 \mathrm{C}$ show example choices from participants represented in this space. Red (blue) dots indicate that the changing (fixed) option was preferred to the fixed (changing) option. As illustrated in these figures, we can use a participant's simple binary choices over this set to draw a single parametric indifference curve, allowing us to estimate whether the utility function and the indifference curve is concave or convex. Critically, this binary-choice-task approach also allows us to use the simple observed pattern of choice to compute a non-parametric estimate of indifference curve by simply averaging the number of red and blue dots in the choice quadrants across subjects. This allows us to make statements about indifference curvature that are unencumbered by assumptions about functional form other than weak monotonicity and continuity. 
In the domain of losses, where we attempted to gather as precise an estimate of the indifference curves as possible, we used a slightly more complex choice set. In the loss domain, we examined 3 complete sets of choices of the kind used in the gain domain. We did this by employing three different "fixed options" and measuring full sets of binary choices against each of these different fixed options. This allowed us to compute three (parametric and non-parametric) indifference curvatures for each subject in the loss domain. The total number of trials use to accomplish this was 92.

The additional "test trials" embedded in the experiment involved choosing between the fixed bundle (black dot in Figure 2A) and a bundle in the yellow or green region, allowing us to assess whether the subject violated the first-order stochastic dominance/monotonicity. We performed test trials in both the gain and loss domain.

\section{Risky choice task}

In the risky choice task, participants made decisions over lotteries with varying levels of risk and reward. What differentiates our study from most is that the rewards were snacks and beverages rather than money. This was essential because we sought to demonstrate the standard prospect theoretic pattern of increasing marginal utilities in the loss domain over the same exact goods used in our bundle measurements. Figure 3 shows example screenshots from risky gain and loss trials. In the panel on the left, the subject offered a choice between a bundle that consists of one more chocolate for sure and $40 \%$ chance of receiving 4 more milk boxes and a bundle that consists of one more chocolate for sure and 10\% chance of receiving 7 more milk boxes. In the situation on the right hand side the subject is choosing between a bundle that implies loosing one chocolate for sure and $40 \%$ of loosing 4 milk boxes and a bundle that would result in loosing one chocolate for sure and $60 \%$ chance of loosing one milk box.

Importantly, in any choice situation both of the options always included one unit of beverage (snack) and a probabilistic quantity of snack (beverage). We designed the choice set this way so that our procedure for risky choice estimated the curvature of the utility function over beverages and snacks (as in the bundle experiment), rather than estimating utility over only one reward type. Just as in the riskless choice task, a "fixed option," this time a lottery, was paired with lotteries that changed from trial-to-trial. As in the riskless trials, there was one fixed option in the gain domain and three fixed options in the loss domain. Table 2 lists the complete choice set. Each question was asked once for the beverage and once for the snack. Overall, participants made 208 choices: 24 for each good in the gain and 68 for each good in the loss domain. There were additional 12 test questions for the beverage and 12 for the snack, where one option was first-order stochastically dominated. For example a choice between option A (one more piece of chocolate for sure and $40 \%$ chance of receiving 4 more boxes of milk ) dominated option B (one more piece of chocolate for sure and $30 \%$ chance of receiving 3 more boxes of milk). 
The important feature of the design was that options were presented to the chooser essentially in the same way in both of the tasks to ensure that any differences we observed were not due to some peculiar experimental confound.

Forty-eight participants (20 male, average age: 23.5 , standard deviation: 4.778) participated in the study. Five participants were excluded from the analysis due to frequent (more than 5 out of 36) violations of first-order stochastic dominance. All participants gave informed consent. The study was conducted at New York University and was approved by the University Committee on Activities Involving Human Subjects at NYU. The participants were recruited using flyers posted in New York University buildings and on the departmental website. The task was programmed using EPrime software. In expectation, participants earned $\$ 20$ and 7.31 beverages and 7.84 snacks for their participation.

\section{Results}

In this section we first use a representative agent approach and show that indifference curves (and the utility functions they imply) do not "reflect" around the origin in the riskless choice task even though for the same subjects utility curves clearly reflect in choice under risk. We show that this result is robust to the modeling specification. We then look into individual behavior and show that it it is consistent with the representative agent results in general but reveals that on the individual level many patterns of behavior exist.

Aggregate level: riskless choice

To estimate the curvature of the utility function for bundles in the riskless choice task we used a constant elasticity of substitution (CES) function. ${ }^{4}$ The utility of a bundle $(\mathrm{x}, \mathrm{y})$ is then given by:

$$
\begin{gathered}
\mathrm{U}(\mathrm{x}, \mathrm{y})=\left(\beta_{\mathrm{g}} \mathrm{x}^{\rho_{\mathrm{g}}}+\left(1-\beta_{\mathrm{g}}\right) \mathrm{y}^{\rho_{\mathrm{g}}}\right)^{\frac{1}{\rho_{\mathrm{g}}}} \text { when } \mathrm{x} \geq 0 \text { and } \mathrm{y} \geq 0 \\
\mathrm{U}(\mathrm{x}, \mathrm{y})=-\left(\beta_{\mathrm{l}}|\mathrm{x}|^{\rho_{1}}+\left(1-\beta_{\mathrm{l}}\right)|\mathrm{y}|^{\rho_{1}}\right)^{\frac{1}{\rho_{1}}} \quad \text { when } \mathrm{x} \leq 0 \text { and } \mathrm{y} \leq 0
\end{gathered}
$$

where $x$ and $y$ are the amounts of beverage and snack respectively and $\beta$ is the distribution parameter, which is within 0 and 1 . The key parameter of interest is $\rho$ as it determines the sign of the second derivative and thus the curvature of the utility function. In the gain domain if $\rho_{\mathrm{g}}$ is smaller (larger) than 1, than the marginal utility is decreasing (increasing). In the loss domain if $\rho_{1}$ is smaller (larger) than 1 , than the marginal utility is increasing (decreasing).

\footnotetext{
${ }^{4}$ We used CES utility function because of its generality (it allows for both convex and concave indifference curves) and popularity examining bundles of goods. It accommodates other popular functional forms such as Cobb-Douglas, linear and Leontief as special cases.
} 
To fit the choice data, we used a logistic choice function, in which the probability that the participant selected a fixed option is given by:

$$
\mathrm{P}(\text { fixed })=\frac{1}{1+e^{-\gamma \Delta U}}
$$

where $\Delta \mathrm{U}$ is the difference in utility of the fixed and changing riskless option and $\gamma$ is the steepness parameter ( $\gamma_{\mathrm{g}}$ for gains and $\gamma_{1}$ for losses).

In contrast with what we take to be the prospect theoretic prediction, we found the marginal utility to be decreasing in both gains and losses, and if anything, decreasing faster in losses than in gains (Fig 4). In the gains $\rho_{\mathrm{g}}$ was smaller than $1\left(\rho_{\mathrm{g}}=0.709 ; 95 \% \mathrm{CI}=0.616-0.802\right)$, and in the losses $\rho_{1}$ was larger than one ( $\left.\rho_{1}=1.572 ; 95 \% \mathrm{CI}=1.477-1.667\right)$. These results are presented in Figure 5A. The distribution parameter $(\beta)$ was essentially the same in the gains and losses $\left(\beta_{g}\right.$ $=0.449 ; 95 \% \mathrm{CI}=0.422-0.4750$ and $\left.\beta_{l}=0.454 ; 95 \% \mathrm{CI}=0.439-0.469\right)$ with participants having preference for approximately equal distribution of each good in the bundle.

To verify that our result is not an artifact of the functional forms that we used, for each bundle we calculated the proportion of times it was selected and a corresponding $95 \%$ confidence interval. We then assessed whether this model-free measure aligns well with our above CES utility function estimates. Figure 6 presents the results as a heat map, where the most (least) frequently selected bundles are in red (blue) and the estimated indifference curves are drawn. We used a binomial distribution to determine whether each particular bundle was preferred or not to the fixed option, assuming that if the bundles were chosen $50 \%$ of the time, this indicates indifference on the aggregate level. Confirming our model-based analysis, all of the bundles that lay on the estimated indifference curve were selected at a proportion not statistically different from $50 \%$ (95\% confidence interval). Empirically, we observed that $97.9 \%$ of the bundles that were below the diagonal line were not preferred to the fixed bundle. We thus conclude that indeed the indifference curves are convex to the origin in gains and concave in losses, consistent with decreasing marginal utility and rate of substitution in both gains and losses. We saw no evidence of a discontinuity that would suggest the existence of a reference point under these conditions.

Aggregate level: risk assessment task

To assess the shape of the utility function under risky conditions, we fitted the data with a power utility function. The expected utility of $x$ units of a good received with probability $p$ is then given by:

$$
\begin{gathered}
\mathrm{EU}(\mathrm{X})=\mathrm{P} * \mathrm{X}^{\alpha_{\mathrm{g}}} \text { when } \mathrm{x} \geq 0 \\
\mathrm{EU}(\mathrm{X})=-\mathrm{P} *|\mathrm{X}|^{\alpha_{1}} \text { when } \mathrm{x} \leq 0
\end{gathered}
$$


where $\alpha_{g}\left(\alpha_{l}\right)$ estimates the curvature of the utility function in the gain (loss) domain. ${ }^{5}$ In gains, $\alpha_{g}>(<) 1$ implies increasing (decreasing) marginal utility. In losses, $\alpha_{l}>(<) 1$ implies decreasing (increasing) marginal utility. We fit the choice data separately for beverages and snacks in the gains and losses using a logistic choice function.

It may seem unusual that we fit a power utility function defined over only one good instead of a CES function defined over two goods because each choice option in our study always included both a snack and a beverage. We selected this approach for the following reasons: First, our approach allows us to estimate the curvature of the utility function separately for beverages and snacks and thus allows us to explicitly test whether the assumption imposed by CES that the exponent for both types of reward is the same is empirically valid. Second, given that the CES utility function is traditionally used for choice under certainty, there is no established practice for its use in risky choice. Third, we believe that the the approach is specifically appropriate for our design. In our risky choice task the quantity and probability of one of the goods was always fixed (at 1 unit received for sure). Finally, to eliminate any doubts regarding our results, we also present a model-free analysis at the end of this section that supports the conclusions of the model-based analysis and makes no parametric assumptions about the structure of the utility curve.

In line with numerous previous studies, we find reflection in the utility curvature - marginal utility is increasing in losses and decreasing in gains both for beverages and for snacks (see Figure $5 \mathrm{~B}$ and $\mathrm{C}$ ). The estimates for each of the goods were not significantly different, suggesting that imposing the same curvature for both goods in the CES utility function is unremarkable. In the gains, we found that $\alpha_{g}=0.522(95 \% \mathrm{CI}=0.475-0.568)$ for beverages and $\alpha_{g}=0.499(\mathrm{CI}=0.452-0.546)$ for snacks, consistent with decreasing marginal utility and risk aversion. In the losses we found $\alpha_{l}=0.923(95 \% \mathrm{CI}=0.874-0.972)$ for beverages and $\alpha_{l}=0.874$ $(95 \% \mathrm{CI}=0.822-0.926)$ for snacks, suggesting increasing marginal utility and risk seeking (Figure 7).

To verify that the result is not confounded by the particular functional forms that we used, we confirm the general trend of risk aversion in gains and risk seeking in losses using perhaps the most intuitive and simple risk measure, the proportion of times that the subject selected the more risky of the two sets of lotteries. In each choice situation, we defined the more risky lottery pair as the one with a higher coefficient of variation $(\mathrm{CV})(\mathrm{CV}=$ standard deviation / |expected value|).

In line with the standard prospect theoretic prediction, we found that majority of participants $(70 \%, 30 / 43)$ selected the risky option in the loss domain more frequently than in the gain domain. The proportion of risky choices for beverages increased significantly from 0.313 $(\mathrm{SD}=0.199$; median=0.333) in the gains to $0.527(\mathrm{SD}=0.216$; median=0.529) in the losses $(\mathrm{t}$ $(42)=-3.834, p<0.0001)$. Similarly, the proportion of risky choices for snacks increased from

\footnotetext{
${ }^{5}$ We have also fitted a traditional power utility function defined over total wealth (where $\mathrm{x}=$ endowment $+/$ - the quantity of the good offered on the current trial). Using the Bayesian information criterion (BIC) we found that the Prospect Theory - type utility model (BIC = $8525.4488)$ fits the data better than utility over total wealth model $(\mathrm{BIC}=10324.953)$.
} 
$0.317(\mathrm{SD}=0.211$; median= 0.292) in the gains to $0.5189(\mathrm{SD}=0.244$; median=0.514 $)$ in the losses $(\mathrm{t}(42)=-3.361, \mathrm{p}=0.002)$.

Summing up, just as in many previous experiments with risky lotteries, an average subject in our study showed decreasing marginal utility (risk aversion) in gains and increasing marginal utility (risk seeking) in losses, a discontinuity that implies a reference point. This happened even though in riskless choice the same participants showed decreasing marginal utility and rates of substitution in both gains and losses, and thus no discontinuity suggestive of a reference point.

Although informative, the representative agent approach presents only averaged and not necessarily even the most frequent pattern of behavior. Therefore, we now turn to the individual level analysis.

\section{Individual level: riskless choice task}

We estimated the parameters of the CES utility function separately for each participant. Participants whose $\rho$ estimates were above 4 or below $10^{\wedge}-8$ were excluded from further analysis. As usually happens, we were not able to fit the data reliably for all of the participants. Overall, we present estimates of 34 (out of 48) participants (who could be well-fit) in this section. Figure $8 \mathrm{~A}$ plots the individual curvature estimates in gains against the estimates in losses. If the traditional reflection effects were to hold, we would expect all of the observations to fall in the gray-shaded region. To the contrary, only 4 out of 34 participants show decreasing marginal utility in gains and increasing marginal utility in losses while the majority of participants, 22 out of 34 showed decreasing marginal utility in both gains and losses. The median of $\rho_{\mathrm{g}}$ is 0.735 and the median of $\rho_{1}$ is 1.505 . There is highly significant negative correlation between the $\rho$ estimate in gains and losses is significant (Pearson coefficient $=-0.61, \mathrm{p}<0.001$ ).

\section{Individual level: risky choice task}

We could reliably fit risky choice task data of 37 (out of 48) participants. We excluded participants with average $\alpha$ estimates that were above 4 or below $10^{\wedge}-8$ from further analysis.

The curvature estimates $(\alpha)$ for beverages and snacks were highly correlated within individuals (Pearson coefficient $=0.873$ in gains and 0.347 in losses, $\mathrm{p}<0.05$ ) so for ease of exposition, for each individual we calculated his average curvature parameter as $\alpha=\left(\alpha_{\text {beverage }}+\alpha_{\text {snack }}\right) / 2$, separately in gains and losses. ${ }^{6}$ Figure 8B plots individual $\alpha$ in gains against $\alpha$ in losses. Under prospect theory we would expect the individuals to fall into the gray region. Indeed, the most frequent pattern ( 18 out of 37 participants) shows the traditional reflection effect. The average of median $\alpha$ is 0.4859 for gains and the average of median $\alpha$ is 0.9693 for losses. In line with the standard prospect theory prediction, there is a positive correlation between the curvature parameter in the gains and losses (Pearson coefficient $=0.395, \mathrm{p}=0.016$ ).

\footnotetext{
${ }^{6}$ The results are qualitatively the same if we perform the analysis separately for beverages and for snacks.
} 


\section{Discussion}

Our key finding is that in the domain of losses, in riskless choice over bundles, our participants show decreasing marginal utility and rate of substitution, rather than increasing, as some have interpreted prospect theory to predict (Thaler 1980; Myagkov and Plott 1997). This happens even though the same participants in the same experimental session show the traditionally observed increasing marginal utility in losses in a risky choice task. These results imply that the reference point might not be present under some conditions of riskless choice.

Critical to understanding this phenomena and its relation to prospect theory is the relationship between marginal rates of substitution and marginal utilities. Traditionally, consumer theory has been concerned mainly with the shape of indifference curves in the domain of gains. The textbook example that introduces the idea of indifference curves explains that because consumers derive less utility from each additional unit of a good, they have convex indifference curves. The logic here is that the more we have of good $\mathrm{x}$ and less of good $\mathrm{y}$, the less of $\mathrm{y}$ we need to give up to maintain the same utility level when we add another unit of $x .{ }^{7}$ Interestingly, how consumer behavior and indifference curves should (in the positive sense) look in the domain of losses and how to relate reference point to riskless choice has been largely ignored in the literature . $^{8}$

A traditional theorist who treats utility (inferred from riskless choice) as an ordinal object defined over the final wealth would consider fundamental changes in indifference curvature as the only compelling evidence for the existence of a reference point. One might well imagine that a reference point could be inferred as a wealth level above which the indifference curves are convex and below which they are concave. Conceptually, one might see this as related to risk seeking (and hence increasing marginal utility) observed in risky choice for decisions below some wealth level, an observation that is at the heart of prospect theory (Myagkov and Plott 1997).

A theorist with a more cardinal view of utility (though admittedly being a cardinal theorist in the domain of riskless choice is conceptually challenging) could infer the existence of the reference point in an additional way. If he were to draw a map of indifference curves, each one util apart,

\footnotetext{
${ }^{7}$ We note that there are widely used utility functions with diminishing marginal utility that result in a constant marginal rate of substitution, for example $\mathrm{U}(\mathrm{x}, \mathrm{y})=\log (\mathrm{x}+\mathrm{y})$, but never in an increasing rate of substitution.

${ }^{8}$ Tversky and Kahneman (1991) acknowledged this puzzle between risky and riskless choice and resolved it by focusing on loss aversion. In that paper they wrote: "in particular, diminishing sensitivity does not imply that the indifference curves are concave below the reference point". Thus for them, changes in the sign of the curvature of the utility function under risk did not necessarily imply changes in the sign of the curvature of the utility function under riskless choice. They proposed instead that it was the cardinal spacing of the indifference curves observed under riskless choice (an admittedly awkward notion) that defined the reference point under these conditions.
} 
then the spacing of these indifference curves could abruptly change at some wealth level / reference point. Above that reference point the curves would be further apart and below it they would be closer together if losses loomed cardinally larger for the chooser than the equally sized gains. Conceptually, one might see this as related to the phenomena of loss aversion in risky choice. Thaler (1980) developed this idea to some degree in his discussion of the endowment effect. We did not pursue this path for identification of reference point in riskless choice for two reasons. First of all, it is not at all clear how to infer loss aversion from riskless choice in a cardinal framework. Indeed, one previous study demonstrated a "disappearance" of loss aversion by evoked by a treatment aimed at reducing subjects' misconceptions about the experimental procedures (Plott and Zeiler, 2005). Even in risky tasks, the existence of loss aversion has been debated (Ert and Erev 2013; Blavatskyy and Pogrebna 2010). Moreover, even if we could overcome these methodological problems and could reliably estimate the spacing of indifference curves between the subjects, Pareto's classic caution regarding comparing utilities within and across individuals applies in a way we find definitively binding.

We therefore, attempted to find evidence of reference dependence in riskless choice by investigating the shape of indifference curves in the domain of gains and losses. Our data reveals that the curvature of the indifference curves in riskless choice does not suddenly change at the current level of endowment - even though we do find such a change under (interleaved) conditions of risky choice. If we did not know where the reference point was and therefore used terminal wealth as the horizontal axis variable and drew the indifference curves of our subjects, the curves would always be the same curvature no matter whether the choices were framed as gains or losses. In other words, we would not find evidence for an ordinally determined reference point in riskless choice over bundles. Our participants did not treat gains and losses differently under certainty even though the same subjects did treat gains and losses differently under conditions of uncertainty.

So why is this the case? At a mechanistic (neuroeconomic) level, what is it that changes the curvature between gains and losses in one of our tasks but not in the other? There are two possible answers: One possibility is that in one of the tasks two elements in the bundle vary and in the other only one element varies from trial-to-trial. (Since we always had two elements in all of the choice options, it cannot simply be because the utility is different for one and two-element choice sets.) The other possibility is that there is something substantially different when we elicit choice under risky and under riskless conditions. Perhaps, the utility function under certainty is different from the utility function under uncertainty. This explanation sits well with emerging findings on the elicitation of time preferences that have begun to reveal that utility elicited under risk seems to be different from the utility elicited from riskless choices (Cheung 2015; Abdellaoui et al. 2013; Andreoni and Sprenger 2012).

We note that our results cannot be captured by other common types of reference dependent preferences. It is true that in our study we carried out our analysis assuming the status quo to be the reference point and many papers have argued that expectation is a better candidate for a reference point (e.g. Koszegi and Rabin). Nevertheless, our results cannot be explained by 
models that define the reference point as an expectation rather than status quo. Firstly, because in our experimental design the expectation does not differ dramatically in our risky and riskless task. Whether in the risky or riskless tasks, subjects should expect to lose when they are in a loss trial and should expect to gain when they are in a gain trial. Secondly, if the reference point was not necessarily the status quo, we should still be able to identify the reference point through the change in the indifference curve curvature at some other level of reward. We do not see evidence of that change in curvature in riskless choice, even though we see a change in utility curvature in our risky task. The tasks do not differ in valence or possession and thus cannot be explained by different types of loss aversion in each task (Brenner et al. 2007). Overall, if one is inclined to consider marginal rates of substitution as reflecting something significant about marginal utilities for the underlying goods, then our data suggest a fundamental change in representation as one moves from risky to riskless conditions.

Such a striking contrast between utility curvature in the loss domain estimated in a task with lotteries versus a riskless choice task is puzzling and seems to run counter to what one might infer from prospect theory. However, the lack of reflection effect in riskless choice may be less surprising than it appears at first. More and more studies in the recent years began to suggest that rather than being a general phenomenon, the reflection effect may depend on context (Laury and Holt 2008; Andreoni and Harbaugh 2009; Harbaugh et al. 2002; Hertwig et al. 2004), and may not be observed when subjects are analyzed at the individual rather than at the aggregate level (Cohen et al. 1987; Schoemaker 1990; Baucells and Villasís 2010; Tymula et al. 2013).

Laury and Holt (2008) found that the occurrence of the reflection effect depends on incentives. Only $13 \%$ of subjects in their study showed the reflection effect when paid for their choices in an incentive compatible way. They also observed that this percentage doubled (26\%) when the payoff was hypothetical. Harbaugh et al. (2002) found that risk attitudes are not consistent with prospect theory when subjects choose between a gamble and its expected value. Andreoni and Harbaugh (2009) pointed out that the identification of reflection effect depends on the econometric approach. In their experiment, 34.1\% subjects showed the reflection effect in a nonparametric test, but only $17 \%$ subjects showed the reflection effect when fitting gain-loss asymmetric power function. And recently, more and more evidence has emerged suggesting a separation in utility under risk and utility under certainty (Cheung 2015). Summing up, it has become increasingly clear that reflection effects are not as general phenomenon as initially suspected. We provide here an additional framework, riskless choice, under which they do not seem to hold.

Our paper also adds evidence to the modest literature on the correlation of individual risk attitudes across different reward types. Experimental economics has traditionally not been able to relate utility curvature for different goods because experimental economists have tended to use only monetary rewards in their experimental studies of decision-making under risk. This of course raises a question about the external validity of the estimates obtained in these studies to different contexts and different reward types. While, some psychological studies have suggested that risks in different domains of decision-making are unrelated (Weber et al. 2002), Levy and 
Glimcher $(2011,2012)$ have suggested that when information as well as procedural and elicitation procedures are controlled for, the utility curvature under risky conditions for different types of rewards are highly correlated within subject.

Summing up, our results suggest that some of the models that were developed to explain decision-making under uncertainty may be inappropriate for modeling choices under certainty. In our data, we did not observe the reflection effect in choice under certainty, which is implied by many reference-dependent utility models. It seems that the concept of the reference point understood as the reflection effect might be required only for decision-making under uncertainty. Our data does not allow us to test for a reference point defined exclusively by loss aversion whether specified as by Kahneman and Tversky (1991) or Koszegi and Rabin (2006). Thus, we do not know if in riskless choice there is a practical reference point in this regard.

\section{Acknowledgement}

We would like to thank Mel Win Khaw for helpful comments, Shannon Rashid for assistance with setting up the experiment and the participants at the 2015 Annual Meeting of the Society for Neuroeconomics, Sydney Experimental Brownbag Seminar, 2015 Annual Meeting of the Society for Neuroscience for valuable comments. The research was sponsored from NIH-NINDSNS054775 grant awarded to P.W.G .. 


\section{References}

Abdellaoui, M., Bleichrodt, H., l'Haridon, O., \& Paraschiv, C. (2013). Is There One Unifying Concept of Utility?An Experimental Comparison of Utility Under Risk and Utility Over Time. Management Science, 59(9), 2153-2169, doi:doi:10.1287/mnsc.1120.1690.

Andreoni, J., \& Harbaugh, W. (2009). Unexpected utility: Experimental tests of five key questions about preferences over risk (Working Paper). Retrieved Aug 15, 2014, from http://econweb.ucsd.edu/ jandreon/WorkingPapers/AndreoniHarbaughUU.pdf.

Andreoni, J., \& Sprenger, C. (2012). Risk Preferences Are Not Time Preferences. American Economic Review, 102(7), 3357-3376, doi:doi: 10.1257/aer.102.7.3357.

Baucells, M., \& Villasís, A. (2010). Stability of risk preferences and the reflection effect of prospect theory. Theory and Decision, 68(1-2), 193-211, doi:10.1007/s11238-009-9153-3.

Blavatskyy, P., \& Pogrebna, G. (2010). Endowment effects?"Even” with half a million on the table! Theory and Decision, 68(1-2), 173-192.

Brenner, L., Rottenstreich, Y., Sood, S., \& Bilgin, B. (2007). On the Psychology of Loss Aversion: Possession, Valence, and Reversals of the Endowment Effect. Journal of Consumer Research, 34(3), 369-376, doi:10.1086/518545.

Cheung, S. L. (2015). Eliciting utility curvature and time preference (Working Paper). School of Economics, The University of Sydney. Retrieved Apr 09, 2015, from http://econwpseries.com/2015/201501.pdf

Cohen, M., Jaffray, J.-Y., \& Said, T. (1987). Experimental comparison of individual behavior under risk and under uncertainty for gains and for losses. Organizational Behavior and Human Decision Processes, 39(1), 1-22, doi:http://dx.doi.org/10.1016/07495978(87)90043-4.

Ert, E., \& Erev, I. (2013). On the descriptive value of loss aversion in decisions under risk: Six clarifications. Judgment and Decision Making, 8(3), 214-235.

Etchart-Vincent, N., \& l'Haridon, O. (2011). Monetary incentives in the loss domain and behavior toward risk: An experimental comparison of three reward schemes including real losses. Journal of Risk and Uncertainty, 42(1), doi:10.1007/s11166-010-9110-0.

Friedman, M., \& Savage, L. J. (1948). The Utility Analysis of Choices Involving Risk. Journal of Political Economy, 56(4), 279-304, doi:10.2307/1826045.

Harbaugh, W. T., Krause, K., \& Vesterlund, L. (2002). Prospect theory in choice and pricing tasks (Working Paper). Retrieved Apr 09, 2015, from file://C:/Users/huikuan/Downloads/SSRN-id436503.pdf

Hertwig, R., Barron, G., Weber, E. U., \& Erev, I. (2004). Decisions from Experience and the Effect of Rare Events in Risky Choice. Psychological Science, 15(8), 534-539, doi:10.1111/j.0956-7976.2004.00715.x.

Kahneman, D., Knetsch, J. L., \& Thaler, R. H. (1991). Anomalies: The Endowment Effect, Loss Aversion, and Status Quo Bias. Journal of Economic Perspectives, 5(1), 193-206, doi:doi: 10.1257/jep.5.1.193.

Kahneman, D., \& Tversky, A. (1979). Prospect Theory: An Analysis of Decision under Risk. Econometrica, 47(2), 263-291, doi:10.2307/1914185.

Knetsch, J. L. (1989). The Endowment Effect and Evidence of Nonreversible Indifference Curves. The American Economic Review, 79(5), 1277-1284, doi:10.2307/1831454.

Köszegi, B., \& Rabin, M. (2006). A Model of Reference-Dependent Preferences. The Quarterly Journal of Economics, 121(4), 1133-1165, doi:10.1093/qje/121.4.1133. 
Laury, S. K., \& Holt, C. A. (2008). Payoff scale effects and risk preference under real and hypothetical conditions. In C. R. Plott, \& V. L. Smith (Eds.), Handbook of experimental economics results (Vol. 1, pp. 1047-1053). New York, NY: Elsevier.

Levy, D. J., \& Glimcher, P. W. (2011). Comparing Apples and Oranges: Using Reward-Specific and Reward-General Subjective Value Representation in the Brain. The Journal of Neuroscience, 31(41), 14693-14707, doi:10.1523/JNEUROSCI.2218-11.2011.

Levy, D. J., \& Glimcher, P. W. (2012). The root of all value: a neural common currency for choice. Current Opinion in Neurobiology, 22(6), 1027-1038, doi:http://dx.doi.org/10.1016/j.conb.2012.06.001.

Myagkov, M., \& Plott, C. R. (1997). Exchange Economies and Loss Exposure: Experiments Exploring Prospect Theory and Competitive Equilibria in Market Environments. The American Economic Review, 87(5), 801-828, doi:10.2307/2951326.

Plott, C. R., \& Zeiler, K. (2005). The Willingness to Pay-Willingness to Accept Gap, the "Endowment Effect," Subject Misconceptions, and Experimental Procedures for Eliciting Valuations. The American Economic Review, 95(3), 530-545, doi:10.2307/4132728.

Schoemaker, P. J. H. (1990). Are Risk-Attitudes Related Across Domains and Response Modes? Management Science, 36(12), 1451-1463, doi:doi:10.1287/mnsc.36.12.1451.

Thaler, R. (1980). Toward a positive theory of consumer choice. Journal of Economic Behavior \& Organization, 1(1), 39-60.

Thaler, R., Tversky, A., Kahneman, D., \& Schwartz, A. (1997). The Effect of Myopia and Loss Aversion on Risk Taking: An Experimental Test. The Quarterly Journal of Economics, 112(2), 647-661, doi:10.1162/003355397555226.

Tversky, A., \& Kahneman, D. (1991). Loss Aversion in Riskless Choice: A ReferenceDependent Model. The Quarterly Journal of Economics, 106(4), 1039-1061, doi: $10.2307 / 2937956$.

Tversky, A., \& Kahneman, D. (1992). Advances in prospect theory: Cumulative representation of uncertainty. Journal of Risk and Uncertainty, 5(4), 297-323, doi:10.1007/BF00122574.

Tymula, A., Rosenberg Belmaker, L. A., Ruderman, L., Glimcher, P. W., \& Levy, I. (2013). Like cognitive function, decision making across the life span shows profound age-related changes. Proceedings of the National Academy of Sciences, 110(42), 17143-17148, doi:10.1073/pnas.1309909110.

Von Neumann, J. V., \& Morgenstern, O. (1944). Theory of games and economic behavior. Princeton, NJ: Princeton University Press.

Weber, E. U., Blais, A.-R., \& Betz, N. E. (2002). A domain-specific risk-attitude scale: measuring risk perceptions and risk behaviors. Journal of Behavioral Decision Making, 15(4), 263-290, doi:10.1002/bdm.414. 


\section{Tables and Figures}

Table 1. Riskless choice task questions. Each fixed option was paired once with each of the variable options in the same raw for a total of 124 unique choice situations. The quantities in the brackets correspond to the quantity of each good (beverage, snack) that was offered.

\begin{tabular}{|c|c|c|}
\hline & Fixed option & Variable option \\
\hline Gain & $(4,4)$ & $\begin{array}{l}(5,3) ;(6,3) ;(7,3) ;(8,3) ;(5,2) ;(6,2) ;(7,2) ;(8,2) \\
(5,1) ;(6,1) ;(7,1) ;(8,1) ;(5,0) ;(6,0) ;(7,0) ;(8,0) \\
(3,5) ;(3,6) ;(3,7) ;(3,8) ;(2,5) ;(2,6) ;(2,7) ;(2,8) \\
(1,5) ;(1,6) ;(1,7) ;(1,8) ;(0,5) ;(0,6) ;(0,7) ;(0,8)\end{array}$ \\
\hline \multirow[t]{3}{*}{ Loss } & $(-3,-3)$ & $\begin{array}{l}(-4,-2) ;(-5,-2) ;(-6,-2) ;(-7,-2) ;(-8,-2) ; \\
(-4,-1) ;(-5,-1) ;(-6,-1) ;(-7,-1) ;(-8,-1) ; \\
(-4,0) ;(-5,0) ;(-6,0) ;(-7,0) ;(-8,0) ;(-2,-4) ;(-2,-5) ;(-2,-6) ;(-2,-7) ;(-2,-8) ; \\
(-1,-4) ;(-1,-5) ;(-1,-6) ;(-1,-7) ;(-1,-8) ;(0,-4) ;(0,-5) ;(0,-6) ;(0,-7) ;(0,-8)\end{array}$ \\
\hline & $(-4,-4)$ & $\begin{array}{l}(-5,-3) ;(-6,-3) ;(-7,-3) ;(-8,-3) ;(-5,-2) ;(-6,-2) ;(-7,-2) ;(-8,-2) \\
(-5,-1) ;(-6,-1) ;(-7,-1) ;(-8,-1) ;(-5,0) ;(-6,0) ;(-7,0) ;(-8,0) \\
(-3,-5) ;(-3,-6) ;(-3,-7) ;(-3,-8) ;(-2,-5) ;(-2,-6) ;(-2,-7) ;(-2,-8) \\
(-1,-5) ;(-1,-6) ;(-1,-7) ;(-1,-8) ;(0,-5) ;(0,-6) ;(0,-7) ;(0,-8)\end{array}$ \\
\hline & $(-5,-5)$ & $\begin{array}{l}(-6,-4) ;(-7,-4) ;(-8,-4) ;(-6,-3) ;(-7,-3) ;(-8,-3) \\
(-6,-2) ;(-7,-2) ;(-8,-2) ;(-6,-1) ;(-7,-1) ;(-8,-1) ; \\
(-6,0) ;(-7,0) ;(-8,0) ;(-4,-6) ;(-4,-7) ;(-4,-8) ;(-3,-6) ;(-3,-7) ;(-3,-8) \\
(-2,-6) ;(-2,-7) ;(-2,-8) ;(-1,-6) ;(-1,-7) ;(-1,-8) ;(0,-6) ;(0,-7) ;(0,-8) .\end{array}$ \\
\hline
\end{tabular}


Table 2. Risky choice task questions. The first number in brackets corresponds to the quantity of the reward, and the second to the odds of receiving this quantity. Each fixed option was paired with each variable option in the same row once for each good type. When the questions were about beverage (snack) one unit of snack (beverage) received with $100 \%$ probability was added to both the fixed and variable option. See Figure 3 for graphical presentation.

\begin{tabular}{|c|c|c|}
\hline & Fixed option & Variable option \\
\hline Gain & $(4,40 \%)$ & $\begin{array}{l}(5,30 \%) ;(6,30 \%) ;(7,30 \%) ;(8,30 \%) ;(5,20 \%) ;(6,20 \%) ; \\
(7,20 \%) ;(8,20 \%) ;(5,10 \%) ;(6,10 \%) ;(7,10 \%) ;(8,10 \%) ; \\
(3,50 \%) ;(3,60 \%) ;(3,70 \%) ;(3,80 \%) ;(2,50 \%) ;(2,60 \%) ; \\
(2,70 \%) ;(2,80 \%) ;(1,50 \%) ;(1,60 \%) ;(1,70 \%) ;(1,80 \%) .\end{array}$ \\
\hline \multirow[t]{3}{*}{ Loss } & $(-3,30 \%)$ & $\begin{array}{l}(-4,20 \%) ;(-5,20 \%) ;(-6,20 \%) ;(-7,20 \%) ;(-8,20 \%) ; \\
(-4,10 \%) ;(-5,10 \%) ;(-6,10 \%) ;(-7,10 \%) ;(-8,10 \%) ; \\
(-2,40 \%) ;(-2,50 \%) ;(-2,60 \%) ;(-2,70 \%) ;(-2,80 \%) ; \\
(-1,40 \%) ;(-1,50 \%) ;(-1,60 \%) ;(-1,70 \%) ;(-1,80 \%) .\end{array}$ \\
\hline & $(-4,40 \%)$ & $\begin{array}{l}(-5,30 \%) ;(-6,30 \%) ;(-7,30 \%) ;(-8,30 \%) ;(-5,20 \%) ;(-6,20 \%) \\
(-7,20 \%) ;(-8,20 \%) ;(-5,10 \%) ;(-6,10 \%) ;(-7,10 \%) ;(-8,10 \%) \\
(-3,50 \%) ;(-3,60 \%) ;(-3,70 \%) ;(-3,80 \%) ;(-2,50 \%) ;(-2,60 \%) ; \\
(-2,70 \%) ;(-2,80 \%) ;(-1,50 \%) ;(-1,60 \%) ;(-1,70 \%) ;(-1,80 \%)\end{array}$ \\
\hline & $(-5,50 \%)$ & $\begin{array}{l}(-6,40 \%) ;(-7,40 \%) ;(-8,40 \%) ;(-6,30 \%) ;(-7,30 \%) ;(-8,30 \%) \\
(-6,20 \%) ;(-7,20 \%) ;(-8,20 \%) ;(-6,10 \%) ;(-7,10 \%) ;(-8,10 \%) ; \\
(-4,60 \%) ;(-4,70 \%) ;(-4,80 \%) ;(-3,60 \%) ;(-3,70 \%) ;(-3,80 \%) ; \\
(-2,60 \%) ;(-2,70 \%) ;(-2,80 \%) ;(-1,60 \%) ;(-1,70 \%) ;(-1,80 \%) .\end{array}$ \\
\hline
\end{tabular}


Figure 1. Sample screenshots from the riskless choice task in the A. gains and B. losses.

A

GAIN 4 boxes of milk AND 4 pieces

of chocolate.

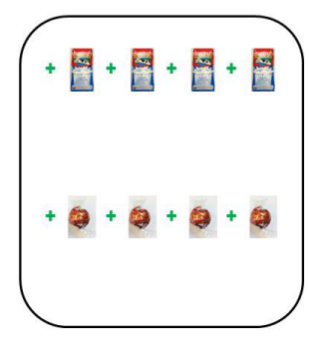

2.

GAIN 1 boxes of milk AND 7 pieces

of chocolate.

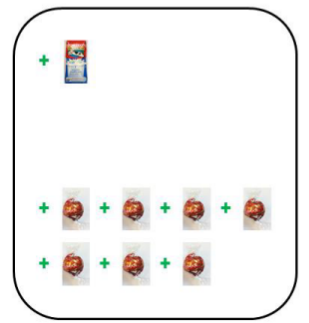

B

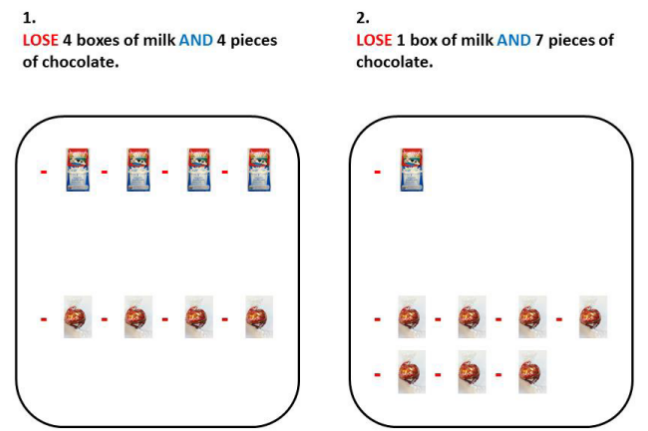

Figure 2. Graphical presentation of the riskless choice task in gains. A: the fixed option was paired with each of the gray dot bundles to form 32 unique choice situations. B: example of a convex indifference curve. $\mathrm{C}$ : example of a concave indifference curve. Red (blue) dots indicate that the subject preferred the other (fixed) bundle to the fixed (other) option.

A

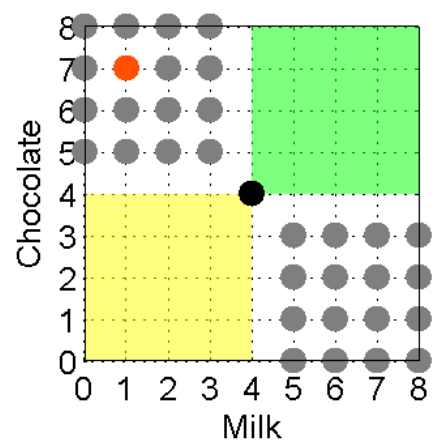

B

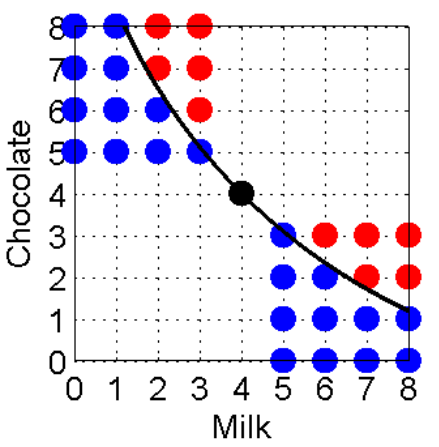

C

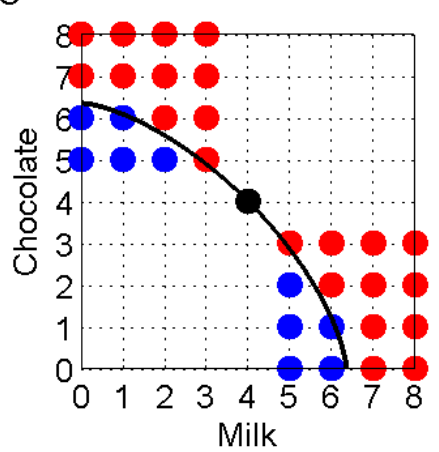


Figure 3. Sample screenshots from the risky choice task in A: gains and B: losses.

A

$100 \%$ chance to GAIN 1 piece of chocolate AND $40 \%$ chance to GAIN 4 boxes of milk.

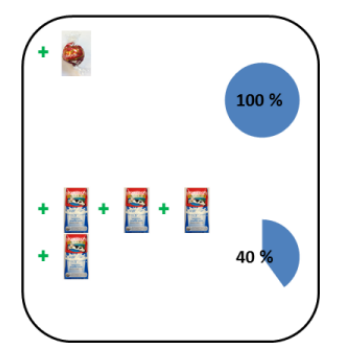

$100 \%$ chance to GAIN 1 piece of chocolate AND $10 \%$ chance to GAIN 7 boxes of milk.

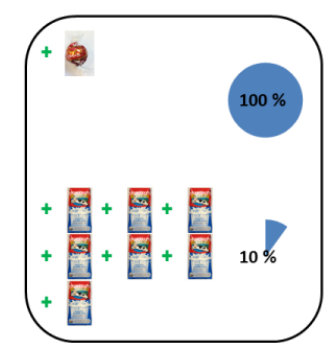

B

$100 \%$ chance to LOSE 1 piece of $\quad 100 \%$ chance to LOSE 1 piece of chocolate AND $40 \%$ chance to LOSE chocolate AND $60 \%$ chance to LOSE 4 boxes of milk. 1 boxes of milk.
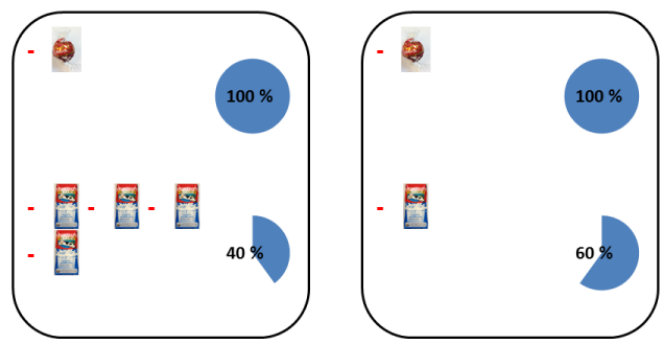

Figure 4. Estimated indifference curves in the gains and losses in the riskless choice task.

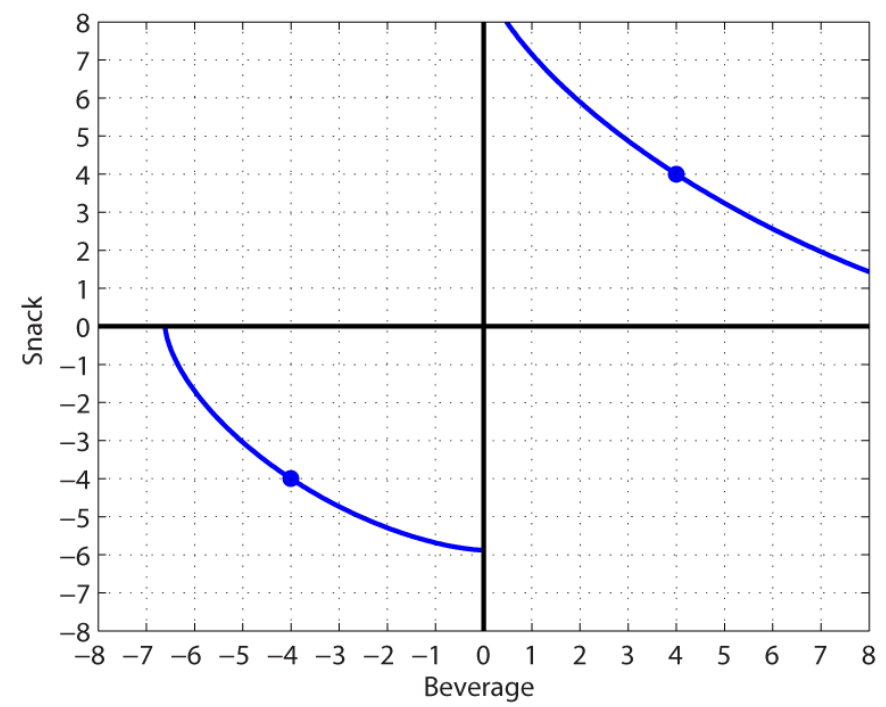


Figure 5. Curvature estimates for A: riskless and $B$ and $C$ : risk choice task. The utility curvature estimates are normalized so that the positive estimates indicate increasing marginal utility and negative estimates indicate decreasing marginal utility (error bars represent the $95 \%$ confidence interval).
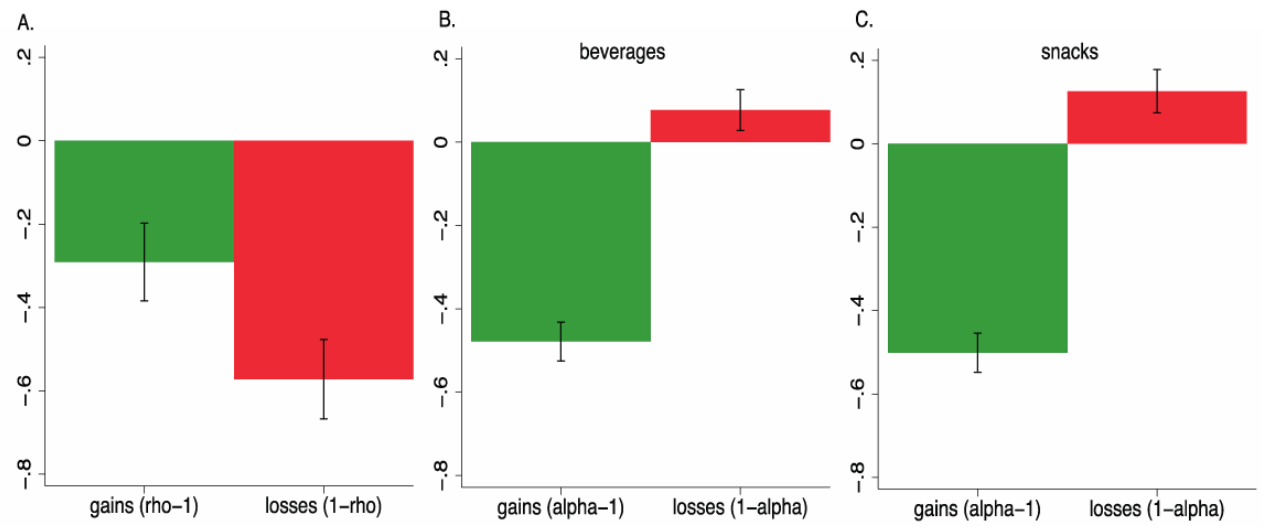

Figure 6. Proportion of times each bundle was selected in the riskless task. The indifference curves drawn here are based on the CES model estimates.
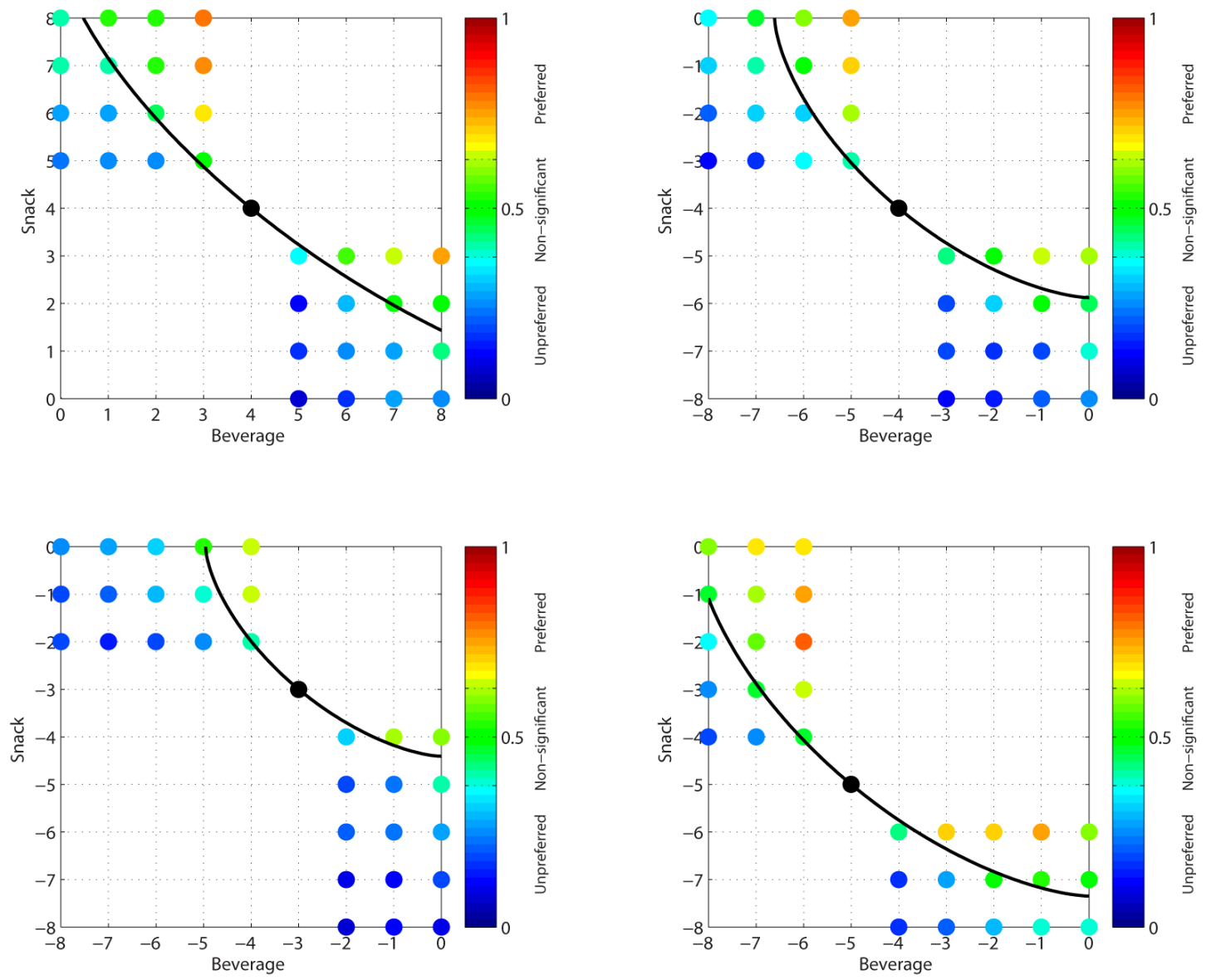
Figure 7. Utility function in the gains and losses in the risky choice task.

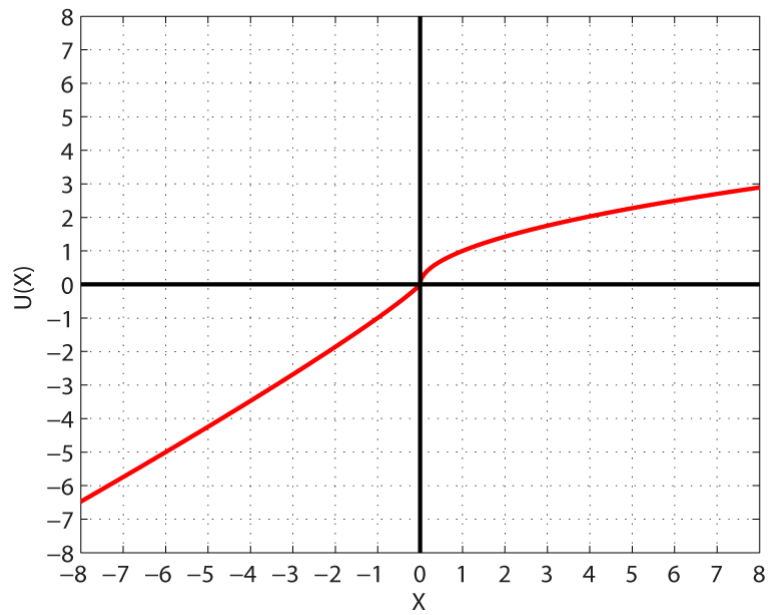

Figure 8. Reflection effects in the A: riskless and B: risky task. The curvature estimates are normalized such that negative (positive) estimates indicate decreasing (increasing) marginal utility. Gray-shaded region indicates estimates consistent with decreasing marginal utility in the gains and increasing marginal utility in losses.

A

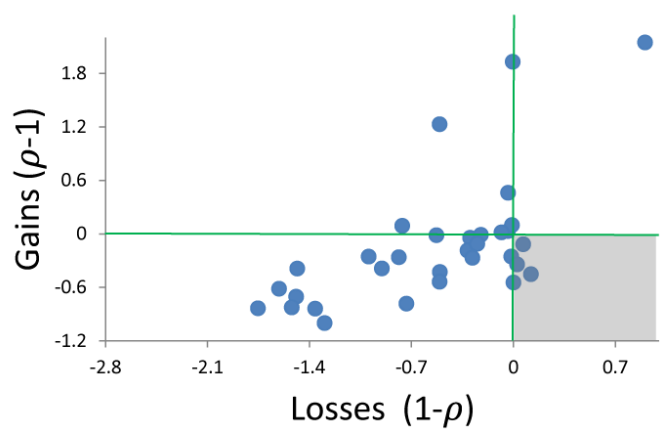

B

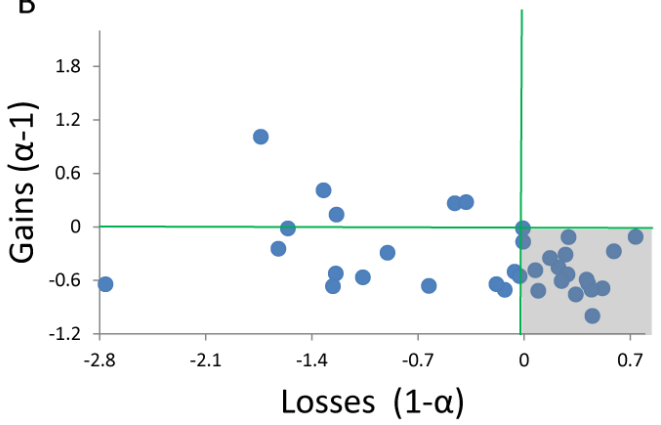




\section{Appendix A - Instructions}

\section{Instructions}

-Welcome! You have received some food from the experimenter. Throughout the study, that food is yours to keep, however, you will be offered the opportunity to make choices that could increase or decrease the amount of food you go home with.

-TASK: Your task on each trial is to choose between two options presented to you on the computer screen. You will be asked to do this many times.

-There is no "right" answer to these questions. We just want to know what you prefer.

-PAYMENT: At the end of the experiment, the computer will randomly select one of the trials, and we will realize it for payment according to your actual choice - so your choices really do matter!

-Please carefully evaluate your options and always choose what you prefer because your payment will be determined by your choices.

\section{Gain and loss trials}

-A green GAIN and the plus symbol $(+)$, means that on this trial you will be receiving more food.

-A red LOSE and the minus symbol (-), means that on this trial you will be losing some of what you already have.

-Questions will be grouped together by whether they concern receiving more (Gain) or losing some of what you already have (Loss).

Example: gain trial

-Suppose you select the option on the left. If this trial is selected for payment, you will receive 4 more boxes of juice and $\mathbf{4}$ more pieces of chocolate.

$$
1 .
$$

1. of chocolate.

2. GAIN 5 boxes of juice AND 3 pieces

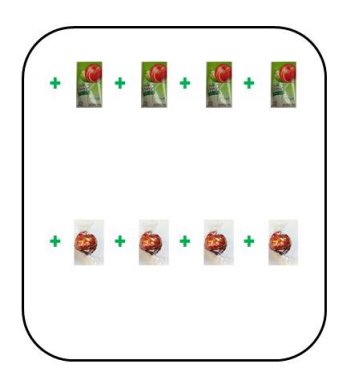




\section{Example: gain trial}

-Suppose you select the option on the right. If this trial is selected for payment, you will receive 5 more boxes of juice but only $\mathbf{3}$ more pieces of chocolate.

GAIN 4 boxes of juice AND 4 pieces

of chocolate.

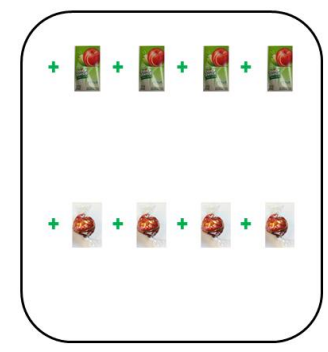

GAIN 5 boxes of juice AND 3 pieces

of chocolate.

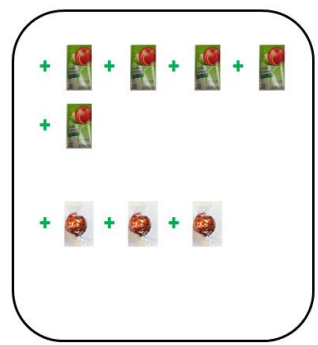

Example: loss trial

-Suppose you select the option on the left. If this trial is selected for payment, you will lose 3 boxes of juice and $\mathbf{3}$ pieces of chocolate from the stock of food you received at the beginning of the experiment.

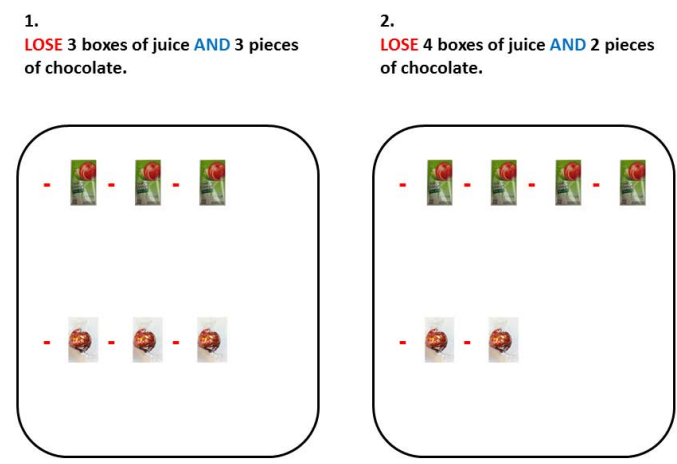

Example: loss trial

-Suppose you select the option on the right. If this trial is selected for payment, you will lose 4 boxes of juice but only $\mathbf{2}$ pieces of chocolate from the stock of food you received at the beginning of the experiment.

LOSE 3 boxes of juice AND 3 pieces of chocolate.

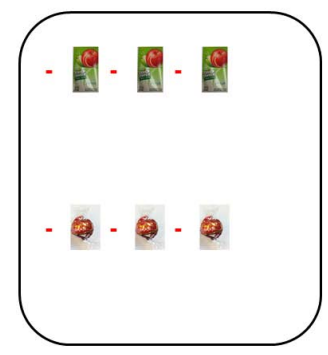

2.

LOSE 4 boxes of juice AND 2 pieces of chocolate.

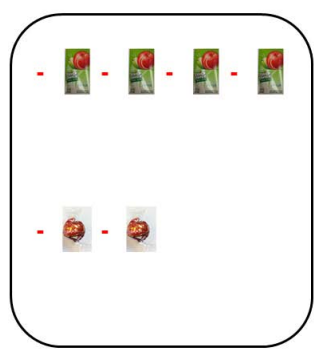




\section{Gamble trials}

-In some trials, the options will involve some degree of uncertainty and will be presented this way:

-This picture represents receiving 1 more box of juice for sure and a $40 \%$ chance of receiving 4 more pieces of chocolate. Whether you receive 4 more pieces of chocolate or not, will depend on whether you "get lucky" when this "chocolate lottery" happens at the end of the experiment.

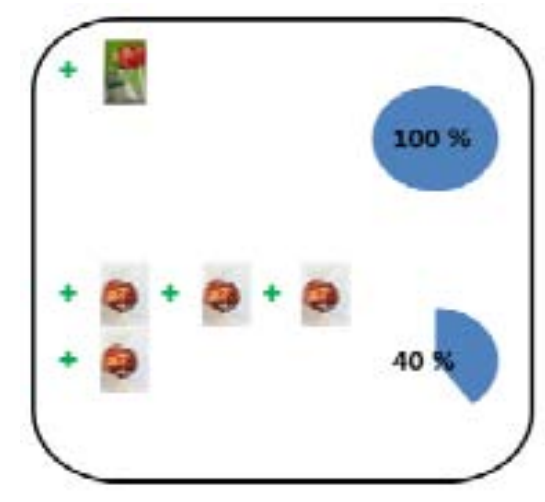

The size of the blue pie charts and numbers represent the likelihood of gaining (or losing) the food items that are next to them.

Gamble trials: gains

-Suppose you select the option on the left. If this trial is selected for payment, you will receive 1 more box of juice for sure (with $100 \%$ probability) and you will have a $\mathbf{4 0 \%}$ chance of receiving 4 more pieces of chocolate as well.

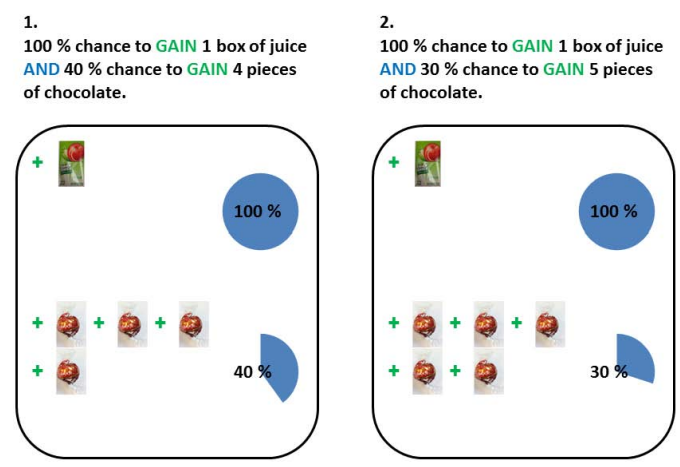


-Suppose you select the option on the right. If this trial is selected for payment, you will receive 1 more box of juice for sure (with 100\% probability) and you will have a $\mathbf{3 0 \%}$ chance of receiving 5 more pieces chocolate as well.

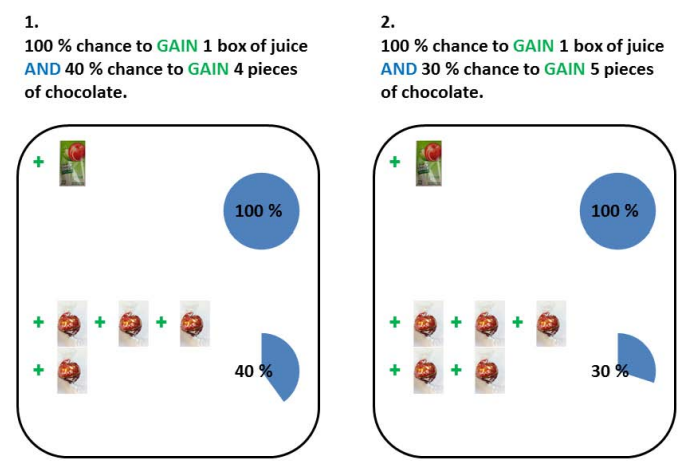

Gamble trials: losses

-Suppose you select the option on the left. If this trial is selected for payment, you will lose 1 of your boxes of juice for sure (with $100 \%$ probability) and you will have a $\mathbf{3 0} \%$ chance of also losing 3 of your pieces of chocolate.
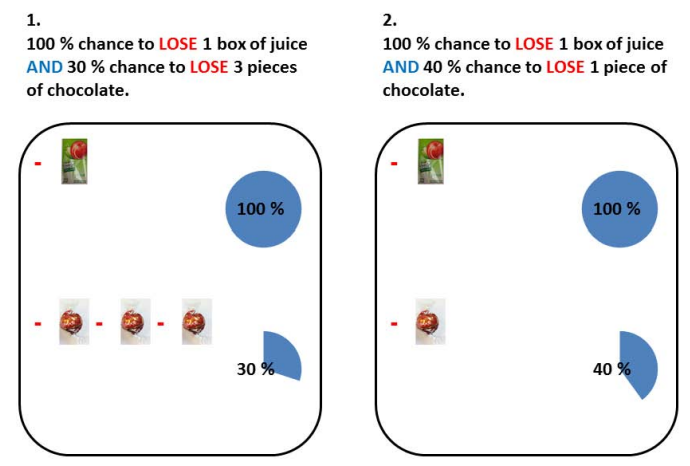
Gamble trials:

losses

-Suppose you select the option on the right. If this trial is selected for payment, you will lose $\mathbf{1}$ of your boxes of juice for sure (with $100 \%$ probability) and you will have a $\mathbf{4 0 \%}$ chance of also losing 1 of your pieces of chocolate.

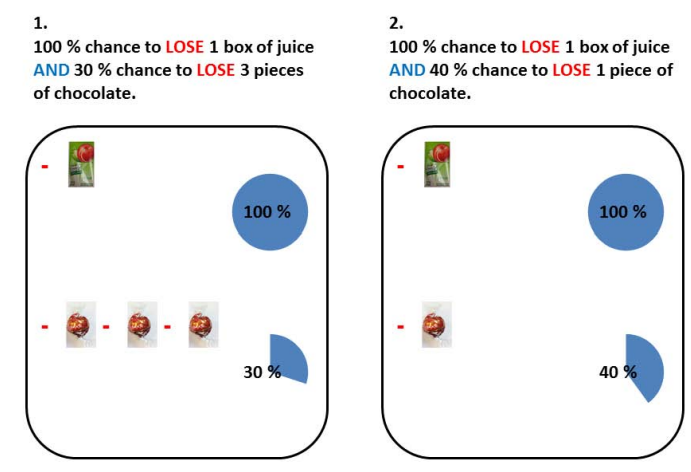

\section{Recognizing gamble trials}

-Remember that in some trials you will not see pie charts. This means that the all the options are certain. Compare:

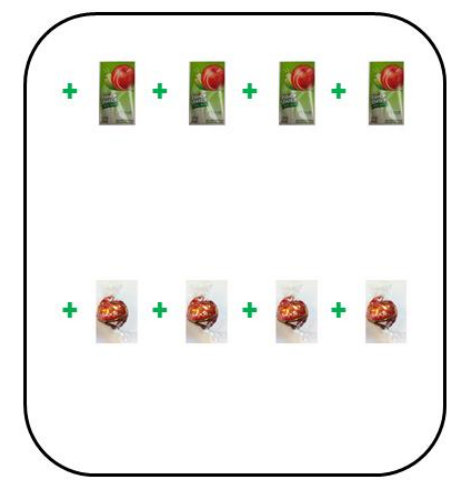

Receive 4 boxes of juice for sure. Receive 4 pieces of chocolate for sure.

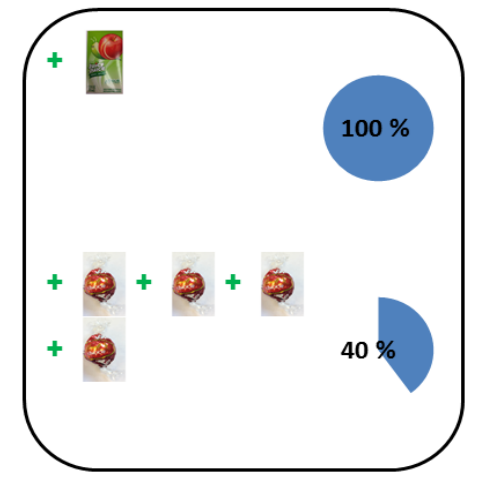

Receive 1 box of juice for sure. Receive 4 pieces of chocolate with $\mathbf{4 0 \%}$ chance. 


\section{Instruction}

-Press " 1 " to select the option on the left. Press " 2 " to select the option on the right. The program will advance to the next trial only after you make your choice. You cannot skip any trials.

-There is no time limit in the experiment, so you should take your time. Remember that any trial could be selected for "realization" so you should consider every trial carefully.

-This is not a test. There are no good or bad answers. It is really important for us that you always choose what you prefer. 